\title{
Enantiopure ferrocene-based planar-chiral Iridacycles: stereospecific control of iridium-centred chirality
}

\author{
Ross Arthurs, ${ }^{[\mathrm{a}]}$ Muhammad Ismail, ${ }^{[\mathrm{a}, \mathrm{b}]}$ Christopher C. Prior, ${ }^{[\mathrm{ad}]}$ Vasily S. Oganesyan, ${ }^{[\mathrm{a}]}$ Peter N. Horton, ${ }^{[\mathrm{c}]}$
} Simon J. Coles ${ }^{[\mathrm{c}]}$ and Christopher J. Richards ${ }^{\star[a]}$

\begin{abstract}
Reaction of $\left[\mathrm{IrCp}^{*} \mathrm{Cl}_{2}\right]_{2}$ with ferrocenylimines $(\mathrm{Fc}=\mathrm{NAr}, \mathrm{Ar}$ $\left.=\mathrm{Ph}, p-\mathrm{MeOC}_{6} \mathrm{H}_{4}\right)$ results in ferrocene $\mathrm{C}-\mathrm{H}$ activation and the diastereoselective synthesis of half-sandwich iridacycles of relative configuration $S_{\mathrm{p}}{ }^{*}, R_{\mathrm{lr}}{ }^{*}$. Extension to (S)-2-ferrocenyl-4-(1methylethyl)oxazoline gave highly diastereoselective control over the new elements of planar chirality and metal-based pseudo-tetrahedral chirality, to give both neutral and cationic half-sandwich iridacycles of absolute configuration $S_{c}, S_{p}, R_{\mathrm{lr}}$. Substitution reactions proceed with retention of configuration, with the planar chirality controlling the metal-centred chirality via an iron-iridium interaction in the coordinatively unsaturated cationic intermediate.
\end{abstract}

\section{Introduction}

Transition metal derived cyclometallated complexes have found many applications in catalysis, energy transfer and biomedical science. ${ }^{1}$ Of the many chiral non-racemic versions known, those displaying planar chirality have two distinctive features that make them especially attractive for further investigation. i) Planar chirality may be obtained efficiently by a one step diastereoselective or enantioselective $\mathrm{C}-\mathrm{H}$ activation reaction of, typically, a ferrocene-based substrate (Scheme 1$)^{2}{ }^{2}$ ii) The metal introduced is then a direct component of the new element of chirality, and as such is in an environment of pronounced asymmetry. Stereoselective $\mathrm{C}-\mathrm{H}$ activation/metallation has been utilised principally with palladium, and the resulting planar-chiral palladacycles are highly enantioselective catalysts for a number of asymmetric organic transformations. ${ }^{3}$ Extension of stereoselective $\mathrm{C}-\mathrm{H}$ activation to the synthesis of other nonracemic planar-chiral metallacycles has to date been limited to cyclomanganation, ${ }^{4}$ cycloplatination ${ }^{5}$ and cyclomercuration. ${ }^{6,7}$

First reported in $1998,{ }^{8}$ iridium(III) half-sandwich

[a] R. Arthurs, C. C. Prior, Dr. V. S. Oganesyan, Dr C. J. Richards School of Chemistry

University of East Anglia

Norwich Research Park, Norwich, NR4 7TJ, U.K.

E-mail: Chris.Richards@uea.ac.uk

[b] Dr M. Ismail.

Current address: Department of Chemistry,

Karakoram International University,

University Road, Gilgit-15100, Pakistan.

[c] Dr. P. N. Horton, Dr. S. J. Coles

EPSRC National Crystallography Service, School of Chemistry,

University of Southampton,

Highfield, Southampton, SO17 1BJ, UK

Supporting information for this article is given via a link at the end of the document. complexes containing an $\eta^{5}$-pentamethylcyclopentadienyl group $\left(\mathrm{Cp}^{*}\right)$, a $\mathrm{C}-\mathrm{N}$ bidentate ligand, and one further neutral or anionic ligand of general structures $\mathbf{1 a / b}$ (Figure 1), have been the subject of many further investigations. ${ }^{9}$ In particular, the recent literature contains numerous reports on the application of such iridacycle complexes to catalytic transformations, ${ }^{10}$ including reactive oxygen species generation for potential cancer chemotherapy. ${ }^{11}$ Non-racemic chiral derivatives are known, ${ }^{8,12}$ as exemplified by oxazoline and imidazoline derivatives $\mathbf{2 a} / \mathbf{b}^{12 f, g, h}$ and amine derivatives $3 .^{12 a-e, h}$ These are frequently obtained as mixtures of diastereoisomers, and the absence of control of the iridium-based stereogenic centre that this reveals is a key factor that has to date limited the impact of these complexes as catalysts in asymmetric synthesis.

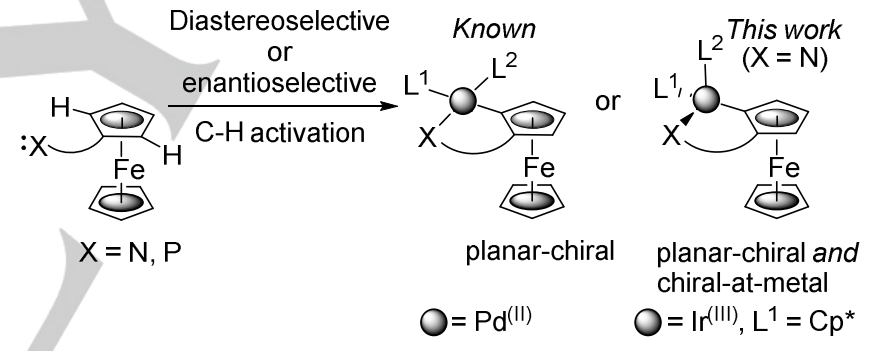

Scheme 1. Stereoselective $\mathrm{C}-\mathrm{H}$ activation as a route to non-racemic ferrocene-based planar-chiral metallacycles.

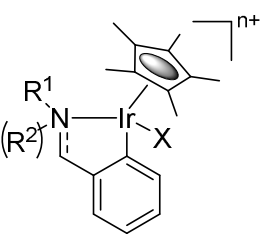

1a $(X=\mathrm{Cl}, \mathrm{n}=0)$ 1b $(X=\operatorname{MeCN}, n=1)$

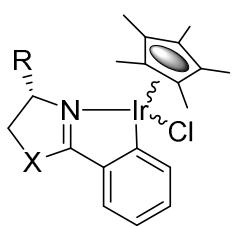

$2 \mathbf{a}(\mathrm{X}=\mathrm{O})$

$\mathbf{2 b}(X=N A r)$

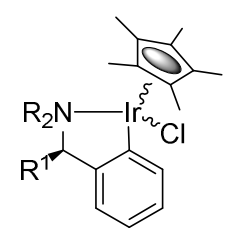

Figure 1. Representative chiral iridacycle half-sandwich complexes.

In this paper we report the synthesis of planar-chiral iridacycles by highly diastereoselective $\mathrm{C}-\mathrm{H}$ activation, with control of the absolute configuration of planar chirality and iridium-centred chirality. 


\section{Results and Discussion}

Two methods are generally employed for the synthesis of halfsandwich iridacycles from $\left[\mathrm{IrCp}^{*} \mathrm{Cl}_{2}\right]_{2}$ by $\mathrm{C}-\mathrm{H}$ activation. Neutral chloride coordinated complexes $1 \mathrm{a}$ are obtained with $\mathrm{NaOAc}$, ligand exchange generating an iridium coordinated acetate which participates in a concerted metallation-deprotonation (CMD) pathway (method 1). ${ }^{12 f}$ Alternatively, addition of $\mathrm{NaOH}$ and $\mathrm{KPF}_{6}$ in $\mathrm{MeCN}$ results in the formation of cationic complexes 1b, with evidence from related reactions pointing again to a CMD pathway via an iridium coordinated hydroxide intermediate (method 2). ${ }^{13}$

Starting with a prochiral ferrocene based substrate $\mathbf{4 a}$, application of method 1 resulted predominantly in $\alpha$-substitution to give ester 5 (Scheme 2). In contrast method 2 gave ferrocenecarboxaldehyde 6 as the major product observed by ${ }^{1} \mathrm{H}$ NMR of the crude product mixture after workup. ${ }^{14}$ Use of primary amine $\mathbf{4 b}$ as the substrate with method 1 resulted in both $\alpha$ substitution, and oxidation to give 5 and 6 in a $0.7: 1$ ratio. The product obtained after workup by method 2 also contained $\mathbf{6}$, with the ${ }^{1} \mathrm{H}$ NMR spectrum also having several signals between 7.48 and $8.65 \mathrm{ppm}$ consistent with a primary aldimine functionality (potentially metal coordinated), although the exact nature of these compounds could not be determined.

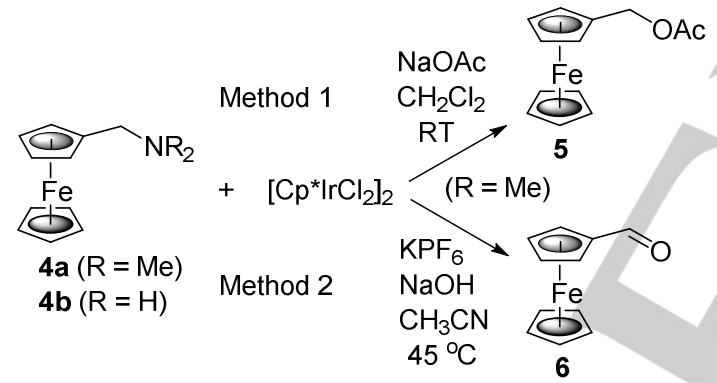

Scheme 2. Attempted cycloiridation of ferrocenylmethylamines.

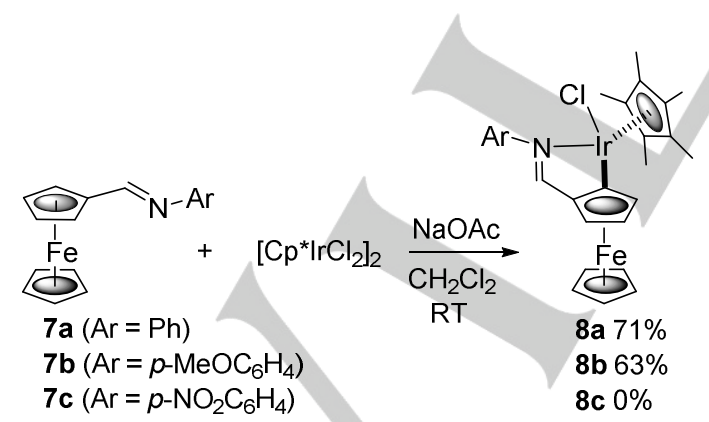

Scheme 3. Cycloiridation of ferrocenylimines $7 \mathbf{a}$ and $\mathbf{7 b}$.

In contrast to benzylamines, ferrocenylmethylamines are clearly unsuitable as substrates for cycloiridation due to enhancement by the metallocene of $\alpha$-substitution ${ }^{15}$ or $\alpha$ hydrogen abstraction. Thus increasing the oxidation level with the use of imine substrates 7a-c was attempted next (Scheme 3). Application of the NaOAc conditions (method 1) with 7a resulted in the generation of a single new species identified as an iridacycle by there being three signals in the ${ }^{1} \mathrm{H}$ NMR for the substituted cyclopentadienyl ring (at 4.61, 4.65 and $4.76 \mathrm{ppm}$ ), the change from 8.34 to $8.15 \mathrm{ppm}$ of the imine proton signal, and the correspondence by integration of these signals to the $\mathrm{Cp}$ (4.12 ppm) and $\mathrm{Cp}^{*}$ (1.59 ppm) singlets. Recrystallisation led to an X-ray structure analysis which confirmed the iridacycle structure of $\mathbf{8 a}$, and revealed the relative configuration as $R_{\mathrm{p}}{ }^{*}, S_{\mathrm{lr}}{ }^{*}$ (Figure 2).

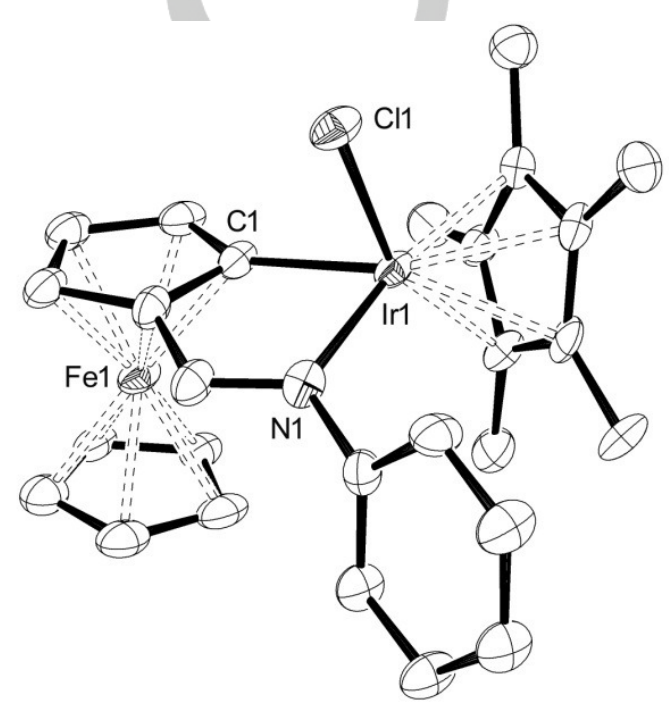

Figure 2. A representation of the X-ray structure of $R_{\mathrm{p}}{ }^{*}, S_{\mathrm{lr}}{ }^{*}-8 \mathrm{a}$ (hydrogen atoms omitted for clarity). Principal bond lengths $[\AA]$ include: $\operatorname{lr}(1)-\mathrm{C}(1)=$ $2.045(10), \operatorname{Ir}(1)-\mathrm{N}(1)=2.107(9), \operatorname{Ir}(1)-\mathrm{Cl}(1)=2.410(2), \operatorname{Ir}(1)-\mathrm{Cp}^{*}$ (centre of mass) $=1.824(5)$. Principal bond angles $\left({ }^{\circ}\right)$ include: $N(1)-\operatorname{Ir}(1)-\mathrm{C}(1)=77.5(4)$, $\mathrm{Cl}(1)-\operatorname{Ir}(1)-\mathrm{C}(1)=86.8(3), \mathrm{Cl}(1)-\operatorname{Ir}(1)-\mathrm{N}(1)=82.5(2), \mathrm{N}(1)-\operatorname{Ir}(1)-\mathrm{Cp}^{*}=135.9(3)$, $C(1)-\operatorname{Ir}(1)-C p^{*}=133.8(3)$.

Imine $\mathbf{7 b}$ was also successfully cycloiridated to give $\mathbf{8 b}$, but changing from a para-methoxy to a para-nitro substituent with imine 7c resulted in no corresponding iridacycle, but instead in the recovery of 7c and ferrocenecarboxaldehyde (ratio $3: 1)$. Thus too great a reduction in the basicity of the imine nitrogen likely correlates with reduced iridium coordination and no cycloiridation. The reaction of imine $7 \mathrm{a}$ using method 2 resulted only in imine hydrolysis and recovery of ferrocenecarboxaldehyde.

\section{Asymmetric synthesis of planar-chiral iridacycles}

One method that may be used to control the absolute configuration of planar chirality generation is auxiliary controlled diastereoselective $\mathrm{C}-\mathrm{H}$ activation. ${ }^{2,16}$ Ferrocenyl oxazoline 9, readily derived from $(S)$-valine, has been demonstrated to undergo highly diastereoselective $\alpha$-lithiation ${ }^{17}$ and $\alpha$ palladation. ${ }^{18}$ Following the reaction of 9 with $\left[\operatorname{IrCp}^{*} \mathrm{Cl}_{2}\right]_{2}, \mathrm{KPF}_{6}$ and an excess (4 equivalents with respect to 9) of $\mathrm{NaOH}$ for 48 $\mathrm{h}$, a new complex was isolated by column chromatography 
(Scheme 4, Table 1, entry 1). In addition to the characteristic signals of a half-sandwich iridacycle, its ${ }^{1} \mathrm{H}$ NMR spectrum contained two doublets $(1 \mathrm{H}, J 15.0)$ at 1.27 and $-0.06 \mathrm{ppm}$. Following recrystallisation, X-ray crystal structure analysis revealed that these ${ }^{1} \mathrm{H}$ NMR signals arise from the diastereotopic geminal hydrogens of the metal-ligated cyanomethyl component of neutral iridacycle $\mathbf{1 0}$ (Figure 3 ). This is one of the four possible diastereoisomers that may be formed on cycloiridation, for which the two new elements of chirality are $S_{p}, R_{\text {Ir }}$. No other iridacycle species were observed by ${ }^{1} \mathrm{H}$ NMR spectroscopic examination of the crude reaction product prior to chromatography.

The $S_{p}$ planar-chiral configuration of 10 , in which the isopropyl group of the oxazoline is orientated towards ferrocene, is the same sense of diastereoselectivity observed previously on metallation. ${ }^{17,18}$ For lithiation, kinetic control is rationalised by approach of the nitrogen-coordinated alkyllithium reagent opposite to both the FeCp component of the metallocene and the isopropyl group of the rotatable oxazoline. ${ }^{17 \mathrm{~b}, 19}$ By extension, the $S_{p}$ configuration of $\mathbf{1 0}$ is also the result of kinetic control, cycloiridation proceeding via exo approach of a nitrogen coordinated iridium species.

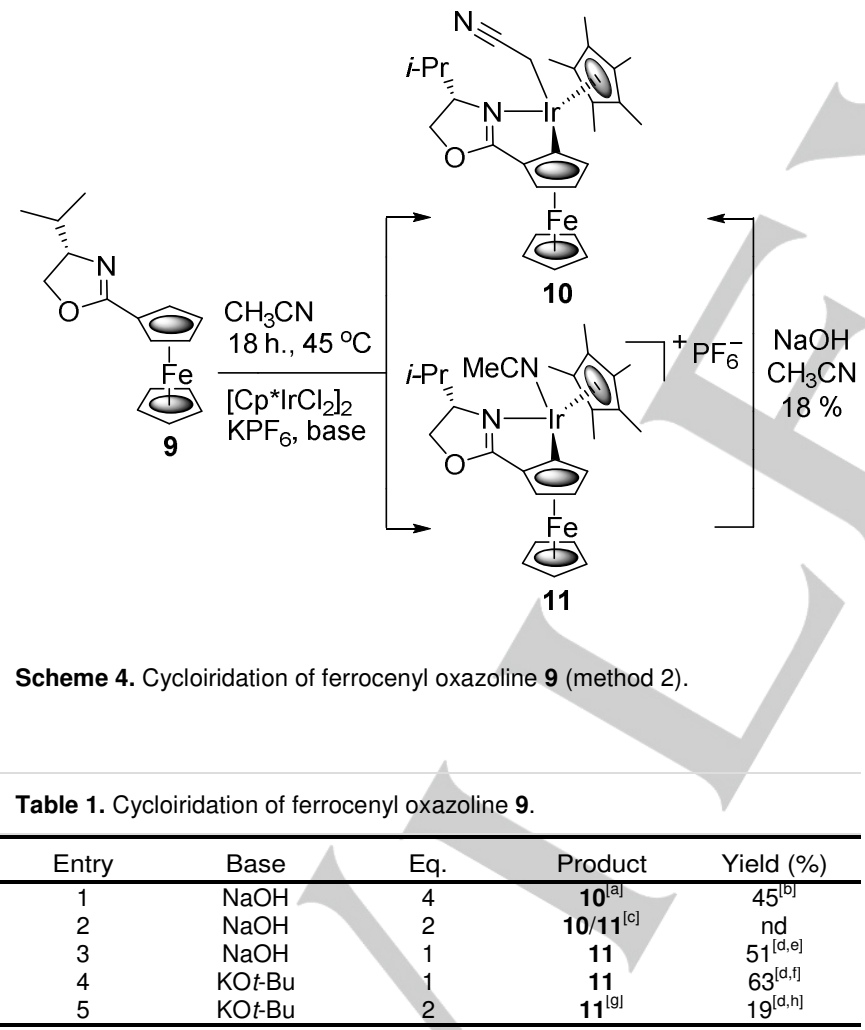

[a] Ratio of $9: 10$ in mixture prior to purification $=1: 1.7$. [b] Isolated by column chromatography $\left(\mathrm{SiO}_{2}\right)$. [c] Ratio 9:10:11 = 1:1:0.1. [d] Isolated by column chromatography $\left(\mathrm{Al}_{2} \mathrm{O}_{3}\right)$. [e] Isolated as a $7: 1$ mixture of isomers. [f] Isolated as a 20:1 mixture of isomers. [g] Ratio 9:10 = 1:0.26. [h] Isolated as a 100:1 mixture of isomers.

The cyanomethyl ligand points to the intermediacy in the reaction of a precursor cationic acetonitrile ligated iridacycle, as other examples of cyanomethyl ligated transition metal complexes have been obtained by acetonitrile deprotonation and ligand flip..$^{20,21}$ Repeating the reaction that gave 10, and following by ${ }^{1} \mathrm{H}$ NMR spectroscopy, revealed a second iridacycle species that disappeared after $48 \mathrm{~h}$. Reducing the $\mathrm{NaOH}$ quantity in the cycloiridation reaction to two equivalents resulted in the isolation of a small quantity of this second iridacycle in addition to $\mathbf{9}$ and 10 (Table 1, entry 2). With one equivalent of $\mathrm{NaOH}$ this new iridacycle was formed as the major product allowing isolation by chromatography on alumina with acetonitrile as the elutent. It was identified as the expected acetonitrile ligated complex 11, and further analysis revealed that this was isolated with a second cationic iridacycle in a ratio of $7: 1$ (entry 3). Replacing very hygroscopic $\mathrm{NaOH}$ with $\mathrm{KOt}$-Bu improved the practicality of the procedure, and with one equivalent of this base the cationic iridacycle 11 was formed in good yield as a 20:1 ratio with the same second complex (entry 4). This ratio increased to 100:1 with two equivalents of $\mathrm{KO} t$ - $\mathrm{Bu}$, albeit with a reduction in overall yield (entry 5). The conversion of $\mathbf{1 1}$ into $\mathbf{1 0}$ was also demonstrated by the reaction of the former with one equivalent of $\mathrm{NaOH}$ in acetonitrile (Scheme 4).

Use of $\mathrm{NaOAc}$ as the base in $\mathrm{CH}_{2} \mathrm{Cl}_{2}$ (i.e. method 1) resulted in partial formation of chloride-ligated iridacycle 12, and even use of excess $\left[\mathrm{IrCp}^{*} \mathrm{Cl}_{2}\right]_{2}$ and $\mathrm{NaOAc}$ led to the isolation of 12 containing a small quantity of starting material (Scheme 5). In contrast to neutral cyanomethyl congener 10, chloride-ligated 12 could not be purified by chromatography on either $\mathrm{SiO}_{2}$ or $\mathrm{Al}_{2} \mathrm{O}_{3}$ due to the formation of an intense blue colour and decomposition (vide infra).

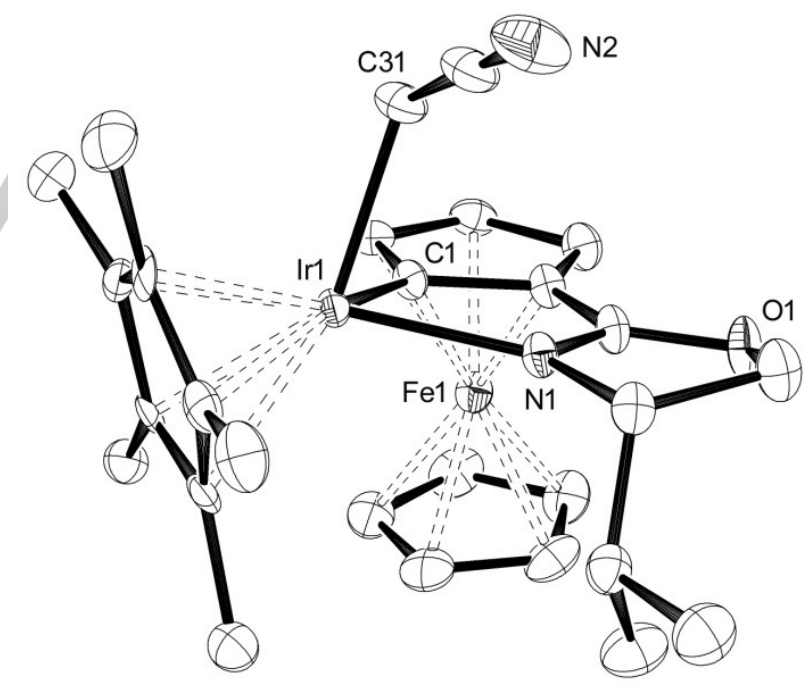

Figure 3. A representation of the X-ray structure of $S, S_{p}, R_{\mathbb{l r}}-10$ (hydrogen atoms omitted for clarity). Principal bond lengths $[\AA]$ include: $\operatorname{lr}(1)-\mathrm{C}(1)=$ 2.056(6), $\operatorname{Ir}(1)-\mathrm{N}(1)=2.093(5), \operatorname{Ir}(1)-\mathrm{C}(31)=2.127(7), \operatorname{Ir}(1)-\mathrm{Cp}^{*}$ (centre of mass) $=1.844(3)$. Principal bond angles $\left({ }^{\circ}\right)$ include: $\mathrm{N}(1)-\operatorname{Ir}(1)-\mathrm{C}(1)=77.8(2)$, $\mathrm{C}(1)-\operatorname{Ir}(1)-\mathrm{C}(31)=81.5(2), \quad \mathrm{N}(1)-\operatorname{Ir}(1)-\mathrm{C}(31)=83.5(2), \quad \mathrm{N}(1)-\operatorname{Ir}(1)-\mathrm{Cp}^{*}=$ 137.05(17), C(1)-Ir(1)-Cp* $=132.93(18)$. 


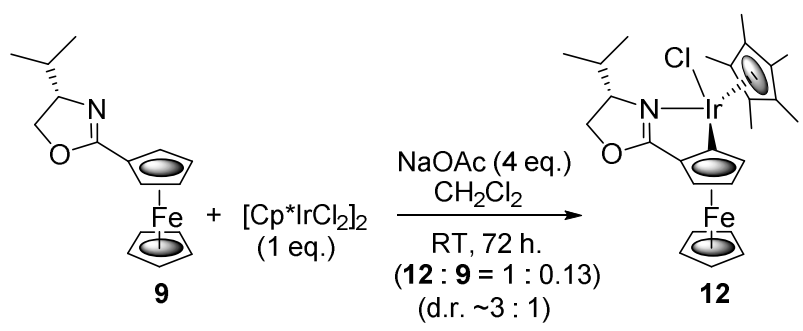

Scheme 5. Cycloiridation of ferrocenyl oxazoline $\mathbf{9}$ (method 1).

Complexes with a diastereomeric relationship to $\mathbf{1 0}$, containing the opposite configuration of planar chirality, were synthesised following prior introduction of a methyl or trimethylsilyl blocking group. Ferrocenyl oxazolines $\mathbf{1 3 a / b}$ were synthesised from 9 by highly diastereoselective lithiation followed by addition of Mel or TMSCI (TMS = trimethylsilyl). ${ }^{17 b, d}$ Subsequent cycloiridation with excess $\mathrm{NaOH}$ gave neutral complexes 14a/b (Scheme 6), and the structure and stereochemistry of the latter product were confirmed by X-ray crystallography (Figure 4). That this was formed by selective C$\mathrm{H}$ over $\mathrm{C}-\mathrm{Si}$ activation is consistent with cycloiridation proceeding via a CMD pathway. The alternative $\mathrm{C}-\mathrm{Si}$ over $\mathrm{C}-\mathrm{H}$ activation, as observed on palladation of trimethylsilyl arenes, is attributed to an electrophilic cyclometallation pathway. ${ }^{22}$

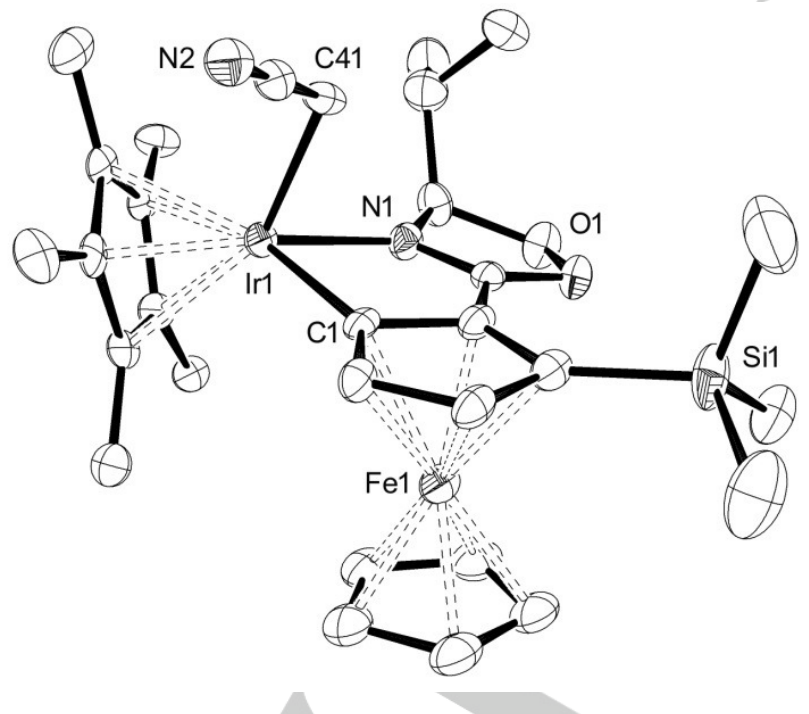

Figure 4. A representation of one of the two different conformations of the $X$ ray structure of $S, R_{\mathrm{p}}, S_{\mid \mathrm{r}}-\mathbf{1 4 b}$ (hydrogen atoms and hexane solvent of crystallisation omitted for clarity). Corresponding values for the second conformation are given in parentheses. Principal bond lengths $[\AA \AA]$ include: $\operatorname{Ir}(1)-\mathrm{C}(1)=2.053(10)[2.043(9)], \operatorname{Ir}(1)-\mathrm{N}(1)=2.095(8)[2.122(8)], \operatorname{Ir}(1)-\mathrm{C}(41)=$ $2.135(11)[2.141(9)], \operatorname{Ir}(1)-\mathrm{Cp}^{*}$ (centre of mass) $=1.849(4)$ [1.847(7)]. Principal bond angles () include: $\mathrm{N}(1)-\operatorname{Ir}(1)-\mathrm{C}(1)=76.3(4)[77.3(4)], \mathrm{C}(1)-\operatorname{Ir}(1)-\mathrm{C}(41)=$ 83.1(4) [81.9(4)], N(1)-Ir(1)-C(41) = 84.5(4) [83.9(4)], N(1)-Ir(1)-Cp* $=133.5(3)$ [134.9(3)], C(1)-Ir(1)-Cp* = 134.7(3) [133.7(3)].

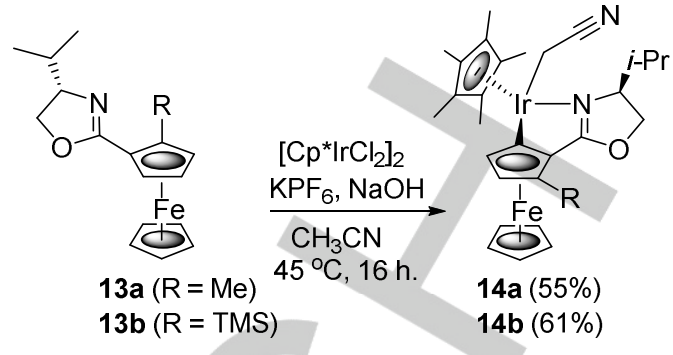

Scheme 6. Cycloiridation of presubstituted ferrocenyl oxazolines $13 \mathbf{a} / \mathbf{b}$.

The X-ray structures of $\mathbf{8 a}, \mathbf{1 0}$ and $\mathbf{1 4 b}$ reveal, respectively, a $R_{\mathrm{p}}{ }^{*}, S_{\mathrm{lr}}{ }^{*}, S_{\mathrm{p}}, R_{\mathrm{lr}}$ and $R_{\mathrm{p}}, S_{\mathrm{lr}}$ relationship between the planar and iridium-centred elements of chirality, such that the $\mathrm{Cp}^{*}$ group is in all cases oriented towards the $\eta^{5}$-cyclopentadienyl group of the metallocene. That this iridium-based configuration is maintained in solution, and is also present in iridacycles $\mathbf{8 b}, \mathbf{1 1}$ and 14a, was established by NOESY experiments which revealed the proximity of the ferrocene $\mathrm{Cp}$ and iridium $\mathrm{Cp}^{*}$ groups (see ESI). This proximity is also the case in the minor isomer formed with 11 on cycloiridation (Table 1, entries 3-5), revealing that this contains a different element of planar chirality [major $(\mathbf{1 1})=S, S_{\mathrm{p}}, R_{\mathrm{l}}$, minor $\left.=S, R_{\mathrm{p}}, S_{\mathrm{l}}\right]$. These data obtained from all the NOESY experiments are consistent with the absence of chiral-at-iridium epimers, and no significant differences were observed in a series of variable temperature ${ }^{1} \mathrm{H}$ NMR experiments with 11 in $\mathrm{CD}_{3} \mathrm{CN}$ between $-40^{\circ} \mathrm{C}$ and $+40{ }^{\circ} \mathrm{C}$. These observations are also consistent with the absence of chiral-at-iridium epimers, assuming that these would give rise to different signals, and that the percentage of a minor isomer is not too small.

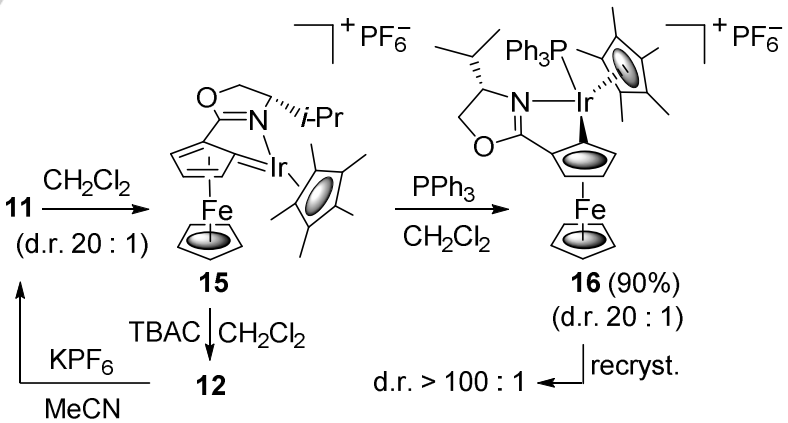

Scheme 7. Stereospecific substitution at iridium via intermediate $\mathbf{1 5 .}$

Conversion of $\mathbf{1 1}$ into $\mathbf{1 0}$ proceeds with retention of configuration. Further investigation into the stereochemistry of ligand substitution (Scheme 7) started with the observation that dissolution of brown/orange 11 (d.r. = $20: 1$ ) in dichloromethane resulted in an intense blue solution $\left(\lambda_{\max }=c a .640 \mathrm{~nm}\right)$. Addition to this of triphenylphosphine resulted in immediate quenching of the intense colour and formation of orange adduct 16 (d.r. $=20$ : 1 - a video of this sequence is available as ESI). Following 
isolation, the iridium-based stereochemistry was again established by a NOESY experiment, and following recrystallisation, confirmed by X-ray crystallography (Figure 5). Thus dissolution of $\mathbf{1 1}$ in dichloromethane, a weakly coordinating solvent, results in what is essentially a coordinatively unsaturated cationic complex 15, with phosphine addition occuring with overall retention of configuration (Scheme 7). ${ }^{23,24}$ Two structures of $\mathbf{1 6}$ are present in the unit cell that differ in the configuration of the coordinated phosphine. The $M$ isomer is represented in Figure $5 .^{25}$ Interconversion of the $M / P$ isomers appears to be rapid at room temperature, as the ${ }^{1} \mathrm{H}$ and ${ }^{31} \mathrm{P}$ NMR spectra of $\mathbf{1 6}$ obtained by recrystallisation each contain only a single set of signals. ${ }^{26}$

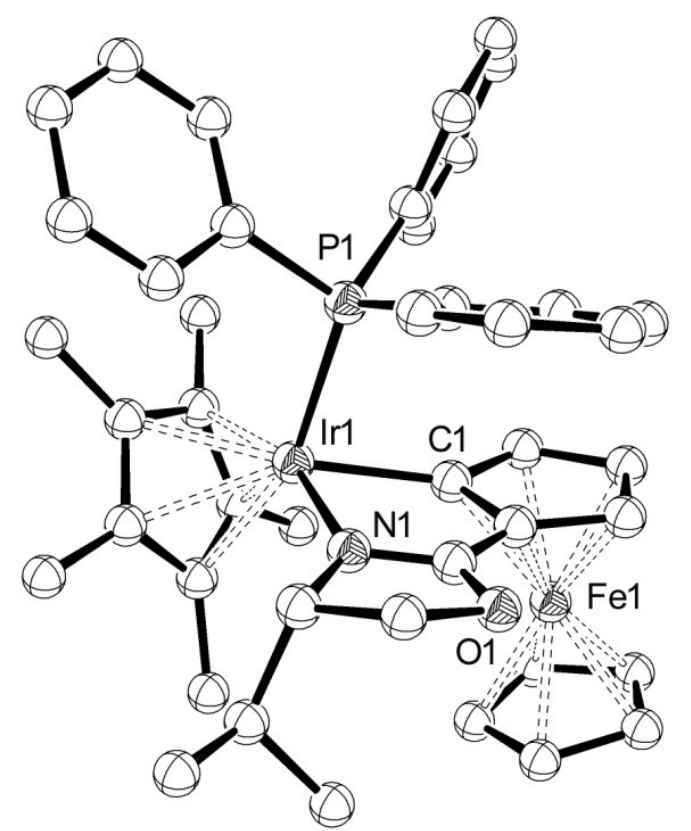

Figure 5. A representation of the X-ray structure of $S, S_{\mathrm{p}}, R_{\mathrm{r}}, M-16$ (hydrogen atoms, hexafluorophosphate anion and chloroform-d solvent of crystallisation omitted for clarity). Corresponding values for $S, S_{\mathrm{p}}, R_{\mathrm{l}}, P-16$ are given in parentheses. Principal bond lengths $[\AA]$ include: $\operatorname{lr}(1)-C(1)=2.082(7)$ $[2.077(7)], \operatorname{Ir}(1)-\mathrm{N}(1)=2.127(5)[2.138(6)], \operatorname{Ir}(1)-\mathrm{P}(1)=2.3173(18)[2.3144(18)]$ $\operatorname{Ir}(1)-\mathrm{Cp}^{*}$ (centre of mass) $=1.885(3)[1.879(3)]$. Principal bond angles $\left({ }^{\circ}\right)$ include: $\mathrm{N}(1)-\operatorname{Ir}(1)-\mathrm{C}(1)=77.2(2)[77.0(3)], \mathrm{C}(1)-\operatorname{Ir}(1)-\mathrm{P}(1)=84.7(2)[86.4(2)]$, $N(1)-\operatorname{Ir}(1)-P(1)=89.39(18)[88.45(18)], N(1)-\operatorname{Ir}(1)-C p^{*}=129.03(18)[131.4(2)]$, $\mathrm{C}(1)-\operatorname{Ir}(1)-C p^{*}=131.0 .(2)[129.7(2)]$

Following dissolution of a further batch of 11 (d.r. = $20: 1$ ) in dichloromethane, addition of tetrabutylammonium chloride (TBAC) again resulted in an immediate change in colour to orange (see ESI), followed by isolation of crude chloride adduct 12. Due to broad signals in the ${ }^{1} \mathrm{H}$ NMR spectrum of this compound the diastereomeric purity was not clear. Addition to 12 of $\mathrm{KPF}_{6}$ in acetonitrile reformed 11 with a d.r. of $20: 1$ revealing no overall stereochemical leakage. Addition of $\mathrm{KPF}_{6}$ in acetonitrile to 12 derived from cycloiridation with $\mathrm{NaOAc}$ as base (Scheme 5 ) gave 11 with a d.r. of $\sim 3: 1$. Thus this cycloiridation method is significantly less selective than those employing $\mathrm{NaOH}$ or $\mathrm{KO}$-Bu.

\section{Computational studies}

A computational investigation was undertaken to determine the relative energy of diastereoisomers containing planar and chiralat-metal elements of chirality, and to further investigate the nature of a coordinatively unsaturated iridium complex. For the former $R_{\mathrm{p}}{ }^{*}, S_{\mathrm{lr}}{ }^{*}-8 \mathrm{a}$ was compared to its corresponding $R_{\mathrm{p}}{ }^{*}, R_{\mathrm{lr}}{ }^{*}$ diastereoisomer 17, and for the latter chloride abstracted complex 18 was studied. All calculations were performed using the Gaussian 09 set of programs ${ }^{27}$ and employing the TaoPerdew-Staroverov-Scuseria (TPSS) ${ }^{28}$ functional. Iridium, iron and chlorine atoms were described using the LAN2LDZ basis set and effective core potential ${ }^{29,30}$ with all other atoms being described with the all electron $6-31+G^{* *}$ basis set. ${ }^{31}$ All structures were optimised in a gas phase and confirmed as minima by frequency analysis with thermodynamic properties extracted for the gas phase at $298.15 \mathrm{~K}$ and $1 \mathrm{~atm}$. Bonding parameters between different pairs of atoms were calculated as the absolute values of the associated non-diagonal elements of the condensed to atoms electron density matrix. (Figure 6, Tables 2-4).

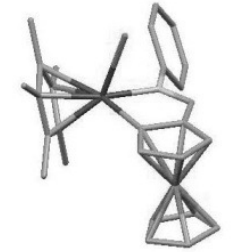

$8 a$

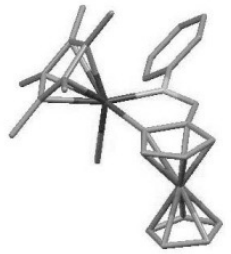

17

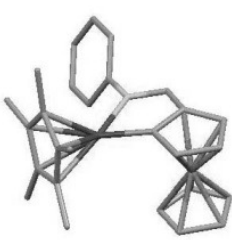

18
Figure 6. Representations of the minimised structures of $8 a, 17$ and 18 (hydrogens ommited for clarity).

The minimum energy structure obtained for $\mathbf{8 a}$ is very similar to that determined by X-ray crystallography. This study revealed that the $R_{\mathrm{p}}{ }^{*}, R_{\mathrm{lr}}{ }^{*}$ diastereoisomer $\mathbf{1 7}$ is lower in energy by $\sim 2 \mathrm{kcal} \mathrm{mol}^{-1}$ than the $R_{\mathrm{p}}{ }^{*}, S_{\mathrm{lr}}{ }^{*}$ diastereoisomer. Thus the generation of this latter observed complex is clearly not under thermodynamic control. Compared to these two chloride adducts, the cationic complex $\mathbf{1 8}$ has a notably shorter Fe-Ir distance of $3.269 \AA$ (Table 2), this arising from a tilt of iridium towards iron of $20.8^{\circ}$ with respect to the plane of the substituted cyclopentadienyl ring, and a shorter Ir-C(Cp) bond length. The iridium-iron bonding parameter of 1.25 in the cationic complex 18 is significantly greater than the value determined for the two chloride diastereoisomers (Table 3). Furthermore, the calculated Mulliken charges reveal a partial delocalisation onto iron for the cation 18 (Table 4). The iron-iridium interaction is illustrated in Figure 7, highlighting the significance of the unsaturated cyclopentadienyl carbon to which both iron and iridium are attached. As a consequence, the vacant iridium-based orbital 
into which a nucleophile adds is oriented away from the iron atom of the ferrocene moiety, resulting in stereospecific addition (Figure 8, Scheme 8). The microreversibility principle requires that loss of a nucleofuge occurs along the same trajectory, such that substitution occurs with overall retention of configuration (which may also be described as a double inversion pathway). The cationic complex $\mathbf{1 8}$ is much more similar in structure to $R_{\mathrm{p}}{ }^{*}, S_{\mathrm{lr}}{ }^{*}$-8a than diastereomeric $R_{\mathrm{p}}{ }^{*}, R_{\mathrm{lr}}{ }^{*}-17$, as revealed by comparison of the N-Ir-Cp* and C-Ir-Cp* bond angles (Table 2). This similarity is also apparent by comparison of the representations of the iridium-based LUMO of $\mathbf{1 8}$ with the $\mathrm{Ir}-\mathrm{Cl}$ bonding orbital in $\mathbf{8 a}$ (Figure 8).

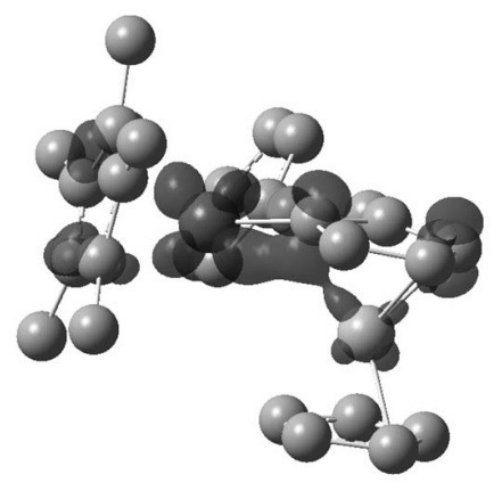

Figure 7. Representation of the iron-iridium interaction in 18.

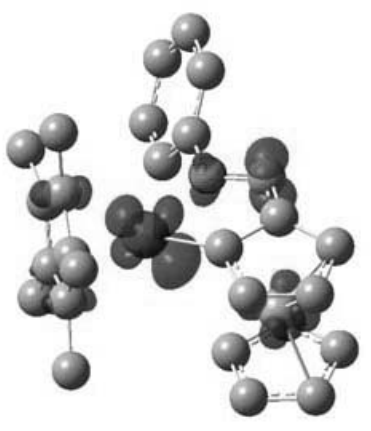

Figure 8. Representations of the iridium-based LUMO of 18 (left) and the $\mathrm{Ir}-\mathrm{Cl}$ bonding orbital in $\mathbf{8 a}$ (right).

Table 2. Selected bond lengths and bond angles of computated iridacycles $\mathbf{8 a}$, 17 and 18.

\begin{tabular}{|c|c|c|c|}
\hline Parameter $^{[a]}$ & $R_{\mathrm{p}}{ }^{*}, S_{\mathrm{Ir}}{ }^{*}-8 \mathrm{a}$ & $R_{\mathrm{p}}{ }^{*}, R_{\mathrm{lr}}{ }^{*}-17$ & Cation-18 \\
\hline $\mathrm{Ir}-\mathrm{Fe}$ & 3.882 & 3.874 & 3.269 \\
\hline Ir-N & 2.124 & 2.140 & 2.117 \\
\hline Ir-C (CpFe) & 2.034 & 2.036 & 1.986 \\
\hline $\mid r-C p^{*[b]}$ & 1.861 & 1.856 & 1.854 \\
\hline $\mathrm{N}-\mathrm{Ir}-\mathrm{C} \mathrm{p}^{*[\mathrm{~b}]}$ & 136.0 & 2.1 & 137.5 \\
\hline C-Ir-Cp ${ }^{*[b]}$ & 135.6 & 130.2 & 139.2 \\
\hline
\end{tabular}

[a] Distances $(\AA)$ angles $\left(^{\circ}\right)$. [b] To the centre of mass of the $\eta^{5}$-ligand.
Table 3. Selected iridium bonding parameters of iridacycles $8 \mathrm{a}, \mathbf{1 7}$ and $\mathbf{1 8}$

\begin{tabular}{cccc}
\hline Bonding parameter for $\mathrm{Ir}$ & $R_{\mathrm{p}}{ }^{*}, \mathrm{~S}_{\mathrm{|r}}{ }^{*}-8 \mathrm{a}$ & $R_{\mathrm{p}}{ }^{*}, R_{\mathrm{lr}}{ }^{*}-17$ & Cation-18 \\
\hline $\mathrm{Ir}-\mathrm{Fe}$ & 0.4 & 0.62 & 1.25 \\
$\mathrm{Ir}-\mathrm{Cl}$ & 0.9 & 0.72 & $\mathrm{n} / \mathrm{a}$ \\
\hline
\end{tabular}

Table 4. Selected Mulliken partial charges of iridacycles $\mathbf{8 a}, \mathbf{1 7}$ and $\mathbf{1 8 .}$

\begin{tabular}{cccc}
\hline Mulliken partial charge & $R_{\mathrm{p}}{ }^{*}, S_{\mid \mathrm{r}}{ }^{*}-\mathbf{8 a}$ & $R_{\mathrm{p}}{ }^{*}, R_{\mid \mathrm{lr}}{ }^{*}-17$ & Cation-18 \\
\hline $\mathrm{Ir}$ & -0.3450 & -0.4512 & 0.6573 \\
$\mathrm{Fe}$ & -1.7807 & -1.7037 & -1.5852 \\
\hline
\end{tabular}

Iridium-centred substitution reactions, via a generalised intermediate of structure 19 (Scheme 8), are related to the substitution reactions of compounds containing a carbon-based stereogenic centre where one of the substituents is a ferrocenyl group (e.g. 20, Scheme 9). Here stereospecific loss of the nucleofuge generates an intermediate a-ferrocenyl carbenium ion 21. X-ray stucture determinations of a number of these blue or purple cationic complexes reveal tilting towards the iron of the a-carbon, with $\mathrm{Fe}-\mathrm{C}(\alpha)$ distances varying between 2.957 and $2.567 \AA .{ }^{32}$ The double bond character of $\mathrm{C}(1)-\mathrm{C}(\alpha)$ slows its rotation which would otherwise result in racemisation. Stereospecific addition of a nucleophile results in the formation of 22 , typically with overall retention of configuration. ${ }^{15}$

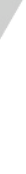

Scheme 8. Stereospecific substitution in planar-chiral iridacycles.

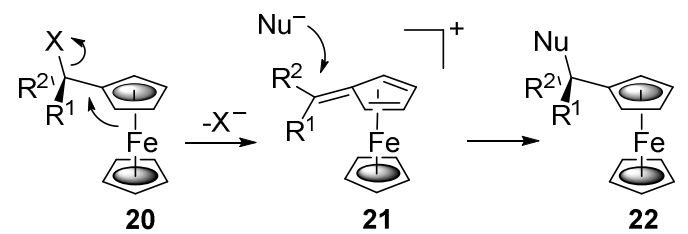

Scheme 9. Stereospecific $\alpha-$ substitution via a configurationally stable $\alpha-$ ferrocenyl carbenium ion.

The formation solely of $R_{\mathrm{p}}{ }^{*}, S_{\mathrm{lr}}{ }^{*}-8 \mathrm{a}$ and $S_{\mathrm{p}}, R_{\mathrm{r}}-10$ (and by extension $R_{\mathrm{p}}, S_{\mathrm{lr}}-\mathbf{1 4 a} / \mathbf{b}$ ) on cycloiridation may also be explained, in part, by the intermediacy of a cationic coordinatively unsaturated complex of general structure 19. The proposal that acetate promoted cycloiridation (method 1) proceeds via the initial formation of an iridium-coordinated acetic acid complex, followed by ligand exchange, ${ }^{12 \uparrow, 33}$ requires the intermediacy of cation 19 for the complexes synthesised in this work (Scheme 
10). A similar water or $t$ - $\mathrm{BuOH}$ coordinated intermediate likely results from the use as base of hydroxide or tert-butoxide repectively. The alternative relative stereochemistry $\left(R_{\mathrm{p}}{ }^{*}, R_{\mathrm{lr}}{ }^{*}\right)$ could also be set during $\mathrm{C}-\mathrm{H}$ activation, and from such an initial structure the formation of $\mathbf{1 9}$ would likely be slower, ${ }^{34}$ but that chloride or acetonitrile complexes are isolated does require ligand substitution to have occurred. Thus the configuration at iridium is set by the kinetic preference for exo ligation due to IrFe interaction in the coordinatively unsaturated precursor.

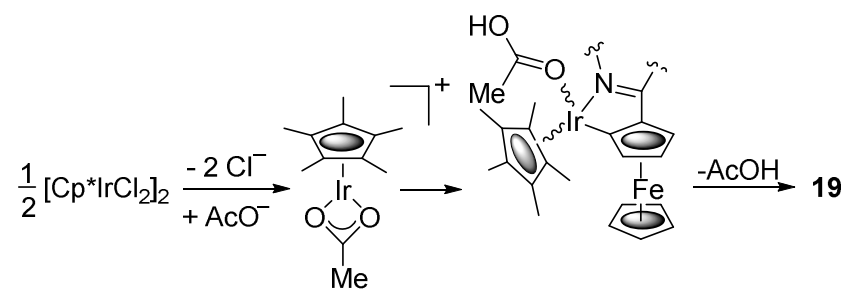

Scheme 10. Components of the cycloiridation pathway to give 19.

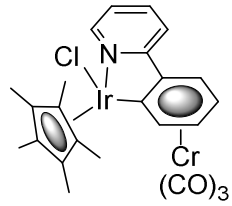

23

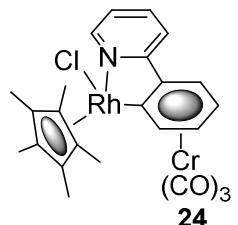

24
Figure 9. Known $\eta^{6}$-arene $/ \mathrm{Cr}(\mathrm{CO})_{3}$-based $\mathrm{Cp}^{*}$-containing metallacycles.

It is of note that the relative stereochemistry of all known (racemic) chromium tricarbonyl $\eta^{6}$-arene based metallacycles containing $\operatorname{IrCp}^{*}$ (e.g. 23) or $\mathrm{RhCp}^{*}$ (e.g. 24) are also exclusively $R_{\mathrm{p}}{ }^{*}, S_{\mathrm{lr}}{ }^{*}$ (Figure 9), ${ }^{35,36}$ and that, in the iridium series, stereospecific substitution has been established via the dissociative formation of a chromium stabilised cationic intermediate. ${ }^{35 b}$ Complexes $\mathbf{2 3}$ and $\mathbf{2 4}$ were synthesised from $\left[\mathrm{Cp}^{*} \mathrm{MCl}_{2}\right]_{2}$ by $\mathrm{C}-\mathrm{H}$ activation with sodium acetate. The stereochemistry is accounted for by the thermodynamic preference for the observed diastereoisomer by the avoidance of an unfavourable dipolar interaction between the chloride ligand and the $\operatorname{Cr}(\mathrm{CO})_{3}$ group that would be present in the $R_{\mathrm{p}}{ }^{*}, R_{\mathrm{M}}{ }^{*}$ epimers. Given that no such thermodynamic preference exists in the ferrocene examples of this work, an alternative explanation is that the metal-based configuration is, in all these cases, a consequence of stereoelectronic kinetic control of ligand coordination.

\section{Conclusions}

Cycloiridation with $\left[\mathrm{Cp}^{*} \mathrm{IrCl}\right]_{2}$ of ferrocenylimines successfully results in $\mathrm{C}-\mathrm{H}$ activation and formation of an iridacycle, avoiding the oxidation or substitution reactions observed with ferrocenylmethylamines as substrates. Only a single diastereoisomer of the product iridacycle is observed with respect to the new planar-chiral and chiral-at-metal stereochemical elements. Extension to cycloiridation of an enantiopure (S)-valine derived ferrocenyl oxazoline results in highly selective formation of one of the four possible diastereoisomers of absolute configuration $S, S_{p}, R_{\mid r}$. Related $S, R_{\mathrm{p}}, S_{\mathrm{lr}}$ configured complexes were synthesised by use of a methyl or TMS blocking group. This first report on the synthesis of enantiopure planar-chiral iridacycles reveals also that the configuration of iridium-centred chirality is controlled by a stereoelectronic effect, a consequence of iron-iridium interaction in the coordinatively unsaturated cationic complex formed on ligand dissociation. Catalysts based on chiral-at-metal complexes are attractive as the metal, which is usually intimately involved in the catalytic pathway, is central to the chirality. ${ }^{37}$ However control of the absolute configuration in pseudotetrahedral complexes has proven to be significant challenge. ${ }^{38,39}$ This work provides a solution through iron-iridium mediated stereospecific ligand substitution, and highly stereoselective control of planar chirality.

\section{Experimental Section}

Representative complexation reaction - preparation of iridacycle 8a: $\mathrm{N}$-Phenyliminomethylferrocene $(0.073 \mathrm{~g}, \quad 0.25 \mathrm{mmol})$, (pentamethylcyclopentadienyl)iridium(III) chloride dimer $(0.100 \mathrm{~g}, 0.13$ $\mathrm{mmol})$ and $\mathrm{NaOAc}(0.023 \mathrm{~g}, 0.28 \mathrm{mmol})$ were added to a flame dried Schlenk tube under an inert atmosphere. Dry $\mathrm{CH}_{2} \mathrm{Cl}_{2}(8 \mathrm{~mL})$ was added and the resulting solution stirred at room temperature for $48 \mathrm{~h}$. Upon completion (reaction progress monitored by ${ }^{1} \mathrm{H}$ NMR), hexane $(20 \mathrm{~mL})$ was added to the reaction and then the reaction mixture filtered through Celite using hexane as the eluent. The solvent was reduced in vacuo until a brown solid became visible around the edges of the roundbottomed flask. At this point the liquid was decanted off and the solids washed with hexane. The decantations and washings were combined and the solvent removed in vacuo. The resulting solid was rinsed with ice cold hexane and dried on a high vacuum line to give a maroon solid $(0.111 \mathrm{~g}, 71 \%)$. The sample for $\mathrm{X}$-ray analysis was obtained by crystallisation from from $\mathrm{CDCl}_{3} /$ hexane: ${ }^{40}$ m.p. $68.0-72.2^{\circ} \mathrm{C} ;{ }^{1} \mathrm{H}$ NMR $\left(500 \mathrm{MHz}, \mathrm{CDCl}_{3}\right) \delta=8.15(\mathrm{~s}, 1 \mathrm{H}, \mathrm{HC}=\mathrm{N}), 7.38(\mathrm{t}, J=7.8 \mathrm{~Hz}, 2 \mathrm{H}, m-\mathrm{PhH})$, 7.32 - $7.28(\mathrm{~m}, 2 \mathrm{H}, o-\mathrm{PhH}), 7.25-7.23(\mathrm{~m}, 1 \mathrm{H}, p-\mathrm{PhH}), 4.76(\mathrm{bs}, 1 \mathrm{H}$, $\mathrm{CpH}$ ), 4.65 (bs, $1 \mathrm{H}, \mathrm{CpH}$ ), 4.61 (bs, $1 \mathrm{H}, \mathrm{CpH}), 4.12$ (s, 5H, $\mathrm{C}_{5} \mathrm{H}_{5}$ ), 1.59 (s, $\left.15 \mathrm{H}, 5 \times \mathrm{CH}_{3}\right) ;{ }^{13} \mathrm{C} \mathrm{NMR}\left(125 \mathrm{MHz}, \mathrm{CDCl}_{3}\right.$ ) $\delta=175.9(\mathrm{C}=\mathrm{N}), 152.9$ (ipso$\mathrm{PhC}), 128.9(o-\mathrm{PhC}), 126.8(p-\mathrm{PhC}), 122.3$ (o-PhC), 98.7 (CpC-Ir), 91.6 $(\mathrm{CpC}-\mathrm{C}=\mathrm{N}), 89.0\left(\mathrm{C}_{5} \mathrm{Me}_{5}\right), 73.5(\mathrm{CpC}), 73.1(\mathrm{CpC}), 68.8\left(\mathrm{C}_{5} \mathrm{H}_{5}\right), 66.9$ (CpC), $9.4\left(\mathrm{CH}_{3}\right)$; IR (film) $\tilde{\mathrm{v}}=3071,2983,2911,1556,1454$; HRMS (AS) $\mathrm{m} / \mathrm{z}$ calcd for $\mathrm{C}_{27} \mathrm{H}_{30} \mathrm{ClFelrN}$ : $652.1033[\mathrm{M}+\mathrm{H}]^{+}$; found 652.1036; elemental analysis calcd (\%) for $\mathrm{C}_{27} \mathrm{H}_{29} \mathrm{CIFelrN}$ : C, 49.81; $\mathrm{H}, 4.49 ; \mathrm{N}$, 2.15; found $\mathrm{C}, 50.01 ; \mathrm{H}, 4.59 ; \mathrm{N}, 2.25$.

\section{Acknowledgements}

The Al-Chem Channel (RA) and the Higher Education Commission Pakistan (M.I.) are thanked for financial support. We also thank the EPSRC National Mass Spectrometry Centre (University of Wales, Swansea). VSO and CCP wish to thank the Research Computing Service at the University of East Anglia for access to the High Performance Computing Cluster. 
Keywords: iridacycle $\bullet$ ferrocene $\cdot$ enantiopure $\cdot$ stereoselective - stereospecific

[1] a) M. Albrecht, Chem. Rev. 2010, 110, 576. b) J. Ruiz, V. Rodríguez, N. Cutillas, K. G. Samper, M. Capdevila, O. Palacios, A. Espinosa, Dalton Trans. 2012, 41, 12847. c) J. Massue, J. Olesiak-Banska, E. Jeanneau, C, Aronica, K. Matczyszyn, M. Samoc, C. Monnereau, C. Andraud, Inorg. Chem. 2013, 52, 10705.

[2] a) J.-P. Djukic, A. Hijazi, H. D. Flack, G. Bernardinelli, Chem. Soc. Rev. 2008, 37, 406. b) C. J. Richards in Chiral Ferrocenes in Asymmetric Catalysis: Synthesis and Applications (Eds.: L.-X. Dai, X.-L. Hou) Wiley-VCH, Weinheim, 2010, pp. 337-368.

[3] a) H. Nomura, C. J. Richards, Chem. Asian J. 2010, 5, 1726. (b) V. V. Dunina, O. N. Gorunova, P. A. Zykov, K. A. Kochetkov, Russ. Chem. Rev. 2011, 80, 51.

[4] a) J.-P. Djukic, A. Maisse, M. Pfeffer, A. de Cian, J. Fischer, Organometallics 1997, 16, 657. b) J.-P. Djukic, A. Maisse, M. Pfeffer, J. Orgmet. Chem. 1998, 567, 65.

[5] a) A. D. Ryabov, I. M. Panyashkina, V. A. Polyakov, J. A. K. Howard, L. G. Kuz'mina, M. S. Datt, C. Sacht, Organometallics 1998, 17, 3615. b) C. López, A. Caubet, S. Pérez, X. Solans, M. Font-Bardía, Chem Commun. 2004, 540. c) C. López, A. Caubet, S. Pérez, X. Solans, M. Font-Bardía, E. Molins, Eur. J. Inorg. Chem. 2006, 3974. d) H. Huang R. Peters, Angew. Chem. Int. Ed. 2009, 48, 604. e) M. E. Günay, D. L. Hughes, C. J. Richards, Organometallics 2011, 30, 3901. f) M. Weiss, W. Frey, R. Peters, Organometallics 2012, 31, 6365.

[6] a) Y. Wu, X. Cui, N. Zhou, M. Song, H. Yun, C. Du, Y. Zhu, Tetrahedron: Asymmetry 2000, 11, 4877. b) A. Berger, A. de Cian, J.-P. Djukic, J. Fischer, M. Pfeffer, Organometallics 2001, 20, 3230.

[7] There are few reports on racemic ferrocene derivatives containing a cyclopentadienyl-carbon iridium bond. Of the following references all but the first describe the formation of this bond by $\mathrm{C}-\mathrm{H}$ activation: a) A. G. Osborne, R. H. Whiteley, J. Organomet. Chem. 1979, 181, 425. b) S. D. Perera, B. L. Shaw, M. Thornton-Pett, J. Chem. Soc. Dalton Trans. 1995, 1689. c) C.-H. Ueng, S.-M. Lu, Inorg. Chim. Acta 1997, 262, 113. d) S. A. Kuklin, A. M. Sheloumov, F. M. Dolgushin, M. G. Ezernitskaya, A. S. Peregudov, P. V. Petrovskii, A. A. Koridze, Organometallics 2006, 25, 5466 .

[8] W. Bauer, M. Prem. K. Polborn, K. Sünkel, W. Steglich, W. Beck, Eur. J. Inorg. Chem., 1998, 485.

[9] Y.-F. Han, G.-X. Jin, Chem. Soc. Rev. 2014, 43, 2799.

[10] Selected examples: a) J. F. Hull, D. Balcells, J. D. Blakemore, C. D. Incarvito, O. Eisenstein, G. W. Brudvig, R. H. Crabtree, J. Am. Chem. Soc. 2009, 131, 8730. b) Y. Kashiwame, S. Kuwata, T. Ikariya, Chem. Eur. J. 2010, 16, 766. c) T. Jerphagnon, R. Haak, F. Berthiol, A. J. A. Gayet, V. Ritleng, A. Holuigue, N. Pannetier, M. Pfeffer, A. Voelklin, L. Lefort, G. Verzijl, C. Tarabiono, D. B. Janssen, A. J. Minnaard, B. L. Feringa, J. G de Vries, Top. Catal. 2010, 53, 1002. d) C. Wang, A. Pettman, J. Bacsa, J. Xiao, Angew. Chem. Int. Ed. 2010, 49, 7548. e) M. Watanabe, Y. Kashiwame, S. Kuwata, T. Ikariya, Eur. J. Inorg Chem. 2012, 504. f) J. Wu, D. Talwar, S. Johnston, M. Yan, J. Xiao, Angew. Chem. Int. Ed. 2013, 52, 6983. g) D. Talwar, N. P. Salguero, C. M. Robertson, J. Xiao, Chem. Eur. J. 2014, 20, 245.

[11] Z. Liu, I. Romero-Canelón, B. Qamar, J. M. Hearn, A. Habtemariam, N. P. E. Barry, A. M. Pizarro, G. J. Clarkson, P. J. Sadler, Angew. Chem. Int. Ed. 2014, 53, 3941.

[12] a) J.-B. Sortais, N. Pannetier, A. Holuigue, L. Barloy, C. Sirlin, M. Pfeffer, N. Kyritsakas, Organometallics 2007, 26, 1856. b) S. Arita, T. Koike, Y. Kayaki, T. Ikariya, Organometallics 2008, 27, 2795. c) S. Arita, T. Koike, Y. Kayaki, T. Ikariya, Angew. Chem. Int. Ed. 2008, 47, 2447. d) L. Barloy, J.-T. Issenhuth, M. G. Weaver, N. Pannetier, C. Sirlin, M. Pfeffer, Organometallics 2011, 30, 1168. e) N. Pannetier, J.-B. Sortais, J.-T. Issenhuth, L. Barloy, C. Sirlin, A. Holuigue, L. Lefort, L. Panella, J. G. de Vries, M. Pfeffer, Adv. Synth. Catal. 2011, 353, 2844. f) Y.
Boutadla, D. L. Davies, R. C. Jones, K. Singh, Chem. Eur. J. 2011, 17 , 3438. g) J. H. Barnard, C. Wang, N. G. Berry, J. Xiao, Chem. Sci. 2013, 4, 1234. h) E. Féghali, L. Barloy, J.-T. Issenhuth, L. Karmazin-Brelot, C. Bailly, M. Pfeffer, Organometallics 2013, 32, 6186.

[13] a) W. J. Tenn, III, K. J. H. Young, J. Oxgaard, R. J. Nielsen, W. A. Goddard, III, R. A. Periana, Organometallics 2006, 25, 5173. b) J. Oxgaard, W. J. Tenn, III, R. J. Nielsen, R. A. Periana, W. A. Goddard, III, Organometallics 2007, 26, 1565.

[14] Attempted cycloiridation of $\mathrm{N}, \mathrm{N}$-dimethylferrocenylethylamine using method 1 resulted in the formation of acetylferrocene and ferrocenylethyl acetate, and using method 2 in the formation of acetylferrocene and vinylferrocene.

[15] G. Gokel, P. Hoffmann, H. Klusacek, D. Marquarding, E. Ruch, I. Ugi, Angew. Chem., Int. Ed. Engl. 1970, 9, 64.

[16] a) C. J. Richards, A. J. Locke, Tetrahedron: Asymmetry 1998, 9, 2377. b) D. Schaarschmidt, H. Lang, Organometallics 2013, 32, 5668.

[17] a) T. Sammakia, H. A. Latham, J. Org. Chem. 1995, 60, 6002. b) C. J. Richards, T. Damalidis, D. E. Hibbs, M. B. Hursthouse, Synlett 1995, 74. c) Y. Nishibayashi, S. Uemura, Synlett 1995, 79. d) C. J. Richards, A. W. Mulvaney, Tetrahedron: Asymmetry 1996, 7, 1419.

[18] J.-B. Xia, S.-L. You, Organometallics 2007, 26, 4869.

[19] A. Škvorcová, R. Šebesta, Org. Biomol. Chem. 2014, 12, 132.

[20] A. M. Oertel, V. Ritleng, M. J. Chetcuti, L. F. Veiros, J. Am. Chem. Soc. 2010, 132, 13588.

[21] Only one example of the X-ray crystal structure of a complex containing an iridium coordinated cyanomethyl ligand has been reported previously: M. G. Crestani, A. Steffen, A. M. Kenwright, A. S. Batsanov, J. A. K. Howard, T. B. Marder, Organometallics 2009, 28, 2904.

[22] J.-M. Valk, J. Boersma, G. van Koten, J. Organomet. Chem. 1994, 483, 213.

[23] Both $\mathrm{CH}_{2} \mathrm{Cl}_{2}$ and $\mathrm{PF}_{6}$ are weakly coordinating: a) T. D. Newbound, $\mathrm{M}$. R. Colsman, M. M. Miller, G. P. Wulfsberg, O. P. Anderson, S. H. Strauss, J. Am. Chem. Soc. 1989, 111, 3762. b) W. Beck, K. Sünkel, Chem. Rev. 1988, 88, 1405.

[24] A very broad ${ }^{1} \mathrm{H}$ NMR spectrum was obtained following the dissolution of 11 in $\mathrm{CD}_{2} \mathrm{Cl}_{2}$.

[25] For $M-16$ the Ir-P-C(ipso)-C (ortho) $<90^{\circ}$ torsions are $7.9^{\circ}, 86.9$ and 53.0. For $P-16$ the corresponding values are $-6.5,-82.3$ and $59.4^{\circ}$.

[26] a) S. E. Garner, A. G. Orpen, J. Chem. Soc., Dalton Trans. 1993, 533. b) H. Brunner, R. Oeschey, B. Nuber, Angew. Chem., Int. Ed. Engl. 1994, 33, 866

[27] Gaussian 09, Revision C.01, M. J. Frisch, G. W. Trucks, H. B. Schlegel, G. E. Scuseria, M. A. Robb, J. R. Cheeseman, G. Scalmani, V. Barone, B. Mennucci, G. A. Petersson, H. Nakatsuji, M. Caricato, X. Li, H. P. Hratchian, A. F. Izmaylov, J. Bloino, G. Zheng, J. L. Sonnenberg, M. Hada, M. Ehara, K. Toyota, R. Fukuda, J. Hasegawa, M. Ishida, T. Nakajima, Y. Honda, O. Kitao, H. Nakai, T. Vreven, J. A. Montgomery, Jr., J. E. Peralta, F. Ogliaro, M. Bearpark, J. J. Heyd, E. Brothers, K. N. Kudin, V. N. Staroverov, R. Kobayashi, J. Normand, K. Raghavachari, A. Rendell, J. C. Burant, S. S. lyengar, J. Tomasi, M. Cossi, N. Rega, J. M. Millam, M. Klene, J. E. Knox, J. B. Cross, V. Bakken, C. Adamo, J. Jaramillo, R. Gomperts, R. E. Stratmann, O. Yazyev, A. J. Austin, R. Cammi, C. Pomelli, J. W. Ochterski, R. L. Martin, K. Morokuma, V. G. Zakrzewski, G. A. Voth, P. Salvador, J. J. Dannenberg, S. Dapprich, A. D. Daniels, Ö. Farkas, J. B. Foresman, J. V. Ortiz, J. Cioslowski, D. J. Fox, Gaussian, Inc., Wallingford CT, USA, 2009.

[28] J. Tao, J. P. Perdew, V. N. Staroverov, G. E. Scuseria, Phys. Rev. Lett. 2003, 91, 146401

[29] P. J. Hay, W. R. Wadt, J. Chem. Phys. 1985, 82, 270.

[30] W. R. Wadt, P. J. Hay, J. Chem. Phys. 1985, 82, 284.

[31] A. Jablonskyte, J. A. Wright, S. A. Fairhurst, J. N. T. Peck, A. K. Ibrahim, V. S. Oganesyan, C. J. Pickett, J Am Chem Soc. 2011, 133, 18606.

[32] a) R. C. Kerber, D. J. Ehntholt, Synthesis 1970, 449. b) S. Lupan, M. Kapon, M. Cais, F. H. Herbstein, Angew. Chem., Int. Ed. Engl. 1972, 11, 
1025. c) V. I. Zdanovich, A. Zh. Seitembetova, V. N. Setkina, Russ. Chem. Rev. 1982, 51, 1157. d) A. Z. Kreindlin, M. A. Rybinskaya, Russ. Chem. Rev. 2004, 73, 417. e) R. Gleiter, C. Bleiholder, F. Rominger, Organometallics 2007, 26, 4850. For related organometallic structures see: e) O. Koch, F. Edelmann, U. Behrens, Chem. Ber. 1982, 115, 1313. f) M. Scheibitz, M. Bolte, J. W. Bats, H.-W. Lerner, I. Nowik, R. H. Herber, A. Krapp, M. Lein, M. C. Holthausen, M. Wagner, Chem. Eur. J. 2005, 11, 584.

[33] L. Li, W. W. Brennessel, W. D. Jones, Organometallics 2009, 28, 3492.

[34] The relative rate of solvolysis in aqueous acetone of exo and endo aacetoxy-1,2-tetramethyleneferrocenylcarbinyl acetate is $2570: 1$. See: E. A. Hill, J. H. Richards, J. Am. Chem. Soc. 1961, 83, 4216.

[35] a) C. Scheeren, F. Maasarani, A. Hijazi, J.-P. Djukic, M. Pfeffer, S. D. Zarić, X.-F. Le Goff, L. Ricard, Organometallics 2007, 26, 3336. b) J.-P. Djukic, C. Boulho, D. Sredojevic, C. Scheeren, S. Zaric, L. Ricard, M. Pfeffer, Chem. Eur. J. 2009, 15, 10830. c) J.-P. Djukic, W. Iali, M. Pfeffer, X.-F. Le Goff, Chem. Eur. J. 2012, 18, 6063.

[36] The same $S_{\mathrm{p}}{ }^{*}, R_{\mathrm{M}}{ }^{*}(\mathrm{M}=\mathrm{Ir}, \mathrm{Rh})$ relative stereochemistry is also observed in chromium tricarbonyl $\eta^{6}$-arene ruthenacycles containing a ruthenium coordinated $\eta^{6}$-cumene (formed by $\mathrm{Hg}$ - $\mathrm{Ru}$ transmetallation): J.-P. Djukic, A. Berger, M. Duquenne, M. Pfeffer, A. De Cian, N. Kyritsakas-Gruber, Organometallics 2004, 23, 5757.

[37] E. B. Bauer, Chem. Soc. Rev. 2012, 41, 3153.

[38] a) V. Alezra, G. Bernardinelli, C. Corminboeuf, U. Frey, E. P. Kündig, A. E. Merbach, C. M. Saudan, F. Viton, J. Weber, J. Am. Chem. Soc. 2004 126, 4843, and references therein. b) J. W. Faller, P. P. Fontaine, Organometallics 2005, 24, 4132.

[39] Configurationally stable $\Lambda$ and $\Delta$ enantiomers of octahedral iridacycle and rhodacycle Lewis acid catalysts obtained by resolution were reported recently: a) H. Huo, C. Fu, K. Harms, E. Meggers, J. Am. Chem. Soc. 2014, 136, 2990. b) C. Wang, L.-A. Chen, H. Huo, X. Shen, K. Harms, L. Gong, E. Meggers, Chem. Sci. 2015, 6, 1094.

[40] CCDC1409985-1409987 and 1412101 contain supplementary X-ray crystallographic data for $\mathbf{8 a}, \mathbf{1 0}, \mathbf{1 4 b}$ and $\mathbf{1 6}$. These data can be obtained free of charge via http://www.ccdc.cam.ac.uk/conts/retrieving.html, or from the Cambridge Crystallographic Data Centre, Union Road, Cambridge, CB2 1EZ; fax(+44) 1223-336-033 or email: deposit@ccdc.cam.ac.uk. 
Layout 2:

\section{FULL PAPER}

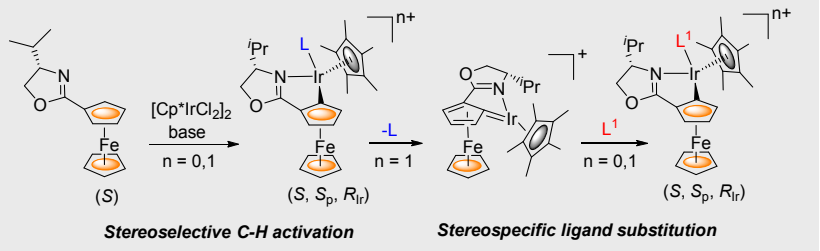

Ross Arthurs, Muhammad Ismail, Christopher C. Prior, Vasily S.

Oganesyan, Peter. N. Horton, Simon J. Coles and Christopher J. Richards*

Page No. - Page No.

Enantiopure ferrocene-based planarchiral iridacycles: stereospecific control of iridium-centred chirality 